Rochester Institute of Technology

RIT Scholar Works

Articles

Faculty \& Staff Scholarship

8-9-2019

\title{
What is the Source of Bilingual Cross-Language Activation in Deaf Bilinguals?
}

\author{
Jill P. Morford \\ University of New Mexico \\ Corrine Occhino \\ Rochester Institute of Technology \\ Megan Zirnstein \\ University of California, Riverside \\ Judith F. Kroll \\ University of California, Riverside \\ Erin Wilkinson \\ University of Manitoba
}

See next page for additional authors

Follow this and additional works at: https://scholarworks.rit.edu/article

\section{Recommended Citation}

Jill P Morford, Corrine Occhino, Megan Zirnstein, Judith F Kroll, Erin Wilkinson, Pilar Piñar, What is the Source of Bilingual Cross-Language Activation in Deaf Bilinguals?, The Journal of Deaf Studies and Deaf Education, Volume 24, Issue 4, October 2019, Pages 356-365, https://doi.org/10.1093/deafed/enz024

This Article is brought to you for free and open access by the Faculty \& Staff Scholarship at RIT Scholar Works. It has been accepted for inclusion in Articles by an authorized administrator of RIT Scholar Works. For more information, please contact ritscholarworks@rit.edu. 


\section{Authors}

Jill P. Morford, Corrine Occhino, Megan Zirnstein, Judith F. Kroll, Erin Wilkinson, and Pilar Piñar 


\title{
What is the Source of Bilingual Cross-Language Activation in Deaf Bilinguals?
}

${ }^{1}$ University of New Mexico ${ }^{2}$ Rochester Institute of Technology ${ }^{3}$ University of California, Riverside ${ }^{4}$ University of Manitoba and ${ }^{5}$ Gallaudet University

${ }^{*}$ Correspondence should be sent to: Jill Morford, University of New Mexico (e-mail: morford@unm.edu)

\begin{abstract}
When deaf bilinguals are asked to make semantic similarity judgments of two written words, their responses are influenced by the sublexical relationship of the signed language translations of the target words. This study investigated whether the observed effects of ASL activation on English print depend on (a) an overlap in syllabic structure of the signed translations or (b) on initialization, an effect of contact between ASL and English that has resulted in a direct representation of English orthographic features in ASL sublexical form. Results demonstrate that neither of these conditions is required or enhances effects of cross-language activation. The experimental outcomes indicate that deaf bilinguals discover the optimal mapping between their two languages in a manner that is not constrained by privileged sublexical associations.
\end{abstract}

The last decade has introduced a stunning change to our understanding of how signing bilinguals process language. Studies of both deaf and hearing signers show that signing bilinguals activate signed language phonology while completing monolingual spoken language reading or listening tasks (Bonsignori \& Demestre, 2018; Chiu, Kuo, Lee \& Tzeng, 2016; Giezen, Blumenfeld, Shook, Marian, \& Emmorey, 2015; Kubuş, Villwock, Morford, \& Rathmann, 2015; Meade, Midgley, Sevcikova Sehyr, Holcomb, \& Emmorey, 2017; Mendoza, Jackson Maldonado, \& Morán, 2018; Morford, Kroll, Piñar, \& Wilkinson, 2014; Morford, Occhino, Piñar, Wilkinson, \& Kroll, 2017; Morford, Wilkinson, Villwock, Piñar, \& Kroll, 2011; Ormel, Hermans, Knoors, \& Verhoeven, 2012; Pan, Shu, Wang, \& Yan, 2015; Quandt \& Kubicek, 2018; Shook \& Marian, 2012; Villameriel, Dias, Costello, \& Carreiras, 2016). Activation of spoken language orthographic representations during signed language processing is also attested (Hosemann, Altvater-Mackensen, Herrman, \& Mani, 2013; Thompson \& Langdon, 2018). These studies challenge the assumption that signed and spoken languages are stored and accessed as fully distinct cognitive systems. These new studies expand our perspective on bilingualism in two ways. First, they demonstrate why we must include minority populations that are generally overlooked or even avoided in the bilingualism literature; in order to fully understand bilingualism, we must study the whole scope of bilingual experience. Second, studies of bilinguals who use a signed language and a spoken language allow us to investigate new dimensions of bilingualism due to little shared articulatory and perceptual systems across these language types. In the context of the substantial evidence of cross-language activation between signed and spoken languages, the current study begins to explore the scope and source of cross-language activation effects in deaf ASL-English bilinguals. Prior studies demonstrate that signers activate signed language phonological forms while reading or listening to spoken languages but do not yet specify whether these effects are widespread across language forms or whether they are driven by privileged sublexical associations.

Studies of cross-language activation in spoken language bilinguals have traditionally investigated whether spoken or written words activate lexical competitors in the nontarget 
language by selecting phonologically or orthographically similar stimuli across the two languages (Nas, 1983; see Schwartz \& Van Hell, 2012 for a review). When bilinguals heard or read word forms drawn from both languages or word forms that were ambiguous with respect to language, such as familiar that has different meanings in Spanish and English, both languages were activated. Evidence of this type has supported the consensus that language processing in bilinguals is largely language nonselective, that is, representations in both languages are accessed during processing, even when bilinguals are interacting with monolinguals who use only one of the bilinguals' languages.

More recently, evidence of nonselective lexical access in bilinguals has been gathered from studies that ask bilinguals to complete monolingual tasks without ambiguous word forms. These studies have relied on implicit cross-language activation of the nontarget language, as seen for example in a study by Thierry and Wu (2007) who asked Chinese-English bilinguals to decide whether or not English word pairs were semantically related. Unbeknownst to participants, the translations of the English words were phonologically or orthographically related in Chinese. Note in this paradigm that related word forms are not manipulated across languages; instead, effects of coactivation are only apparent if two related word forms within the nontarget language are activated. Participants showed no behavioral effects of the implicit relationship in Thierry and Wu (2007), but the ERP record revealed that bilinguals were unconsciously activating the Chinese translations while completing the English-only task. A subsequent investigation by Wu and Thierry (2010) found that it was the phonological rather than the orthographic relationship between the Chinese translations that was responsible for the effect.

The introduction of implicit priming studies opened the gateway to investigating cross-language activation in signing bilinguals. Studies of nonselective access in signing bilinguals cannot depend on language-ambiguous stimuli to demonstrate parallel activation: signs and words are perceptually distinct. Instead, studies of cross-language activation in signing bilinguals rely on implicit priming, as in the Thierry and Wu (2007) study, or on picture-word verification tasks, in which a picture could potentially activate lexical forms in either the signed or the spoken language. In the first study to provide evidence that deaf bilinguals activate ASL signs while processing English print, participants were asked to view two English words and decide whether or not they were semantically related (Morford et al., 2011). ASL translations of half of the target word pairs shared two of three phonological parameters: handshape and movement (SUMMER-UGLY), handshape and location (PAPER-MOVIE), or movement and location (BUTTER-SOAP). Deaf bilinguals were faster to decide that two English words were semantically related when the ASL translations of the stimuli were phonologically related. For semantically unrelated words, by contrast, the implicit ASL relationship slowed response time.

Ormel et al. (2012) used picture-word verification to provide the first evidence that deaf children developing proficiency in a signed and a spoken language also experience cross-language activation. Deaf children acquiring Dutch and Sign Language of the Netherlands (NGT) were shown a colored line drawing and a Dutch word and asked to decide whether or not the word described the picture. When the NGT name of the picture shared a combination of handshape, movement, location, and/or palm orientation with the actual NGT translation of the Dutch word, children were slower to reject the Dutch word as a name for the picture relative to a control word. In all subsequent studies since these original demonstrations of cross-language activation in deaf bilinguals, there has been no attempt to explore what phonological dimensions were contributing to the coactivation of signs by written words (Bonsignori \& Demestre, 2018; Chiu et al., 2016; Kubuş et al., 2015; Morford et al., 2014; Meade et al., 2017; Mendoza et al., 2018; Pan et al., 2015).

Our goal in the current study is to explore whether certain sublexical patterns are privileged in cross-language interactions. To investigate this question, we attempt to replicate prior studies showing evidence of cross-language activation in a semantic judgment task involving English word pairs with ASL translations that share different sublexical dimensions. If crosslanguage activation is only found under specific conditions, then we can identify what underlies this bilingual phenomenon. If, by contrast, cross-language activation is persistent in the absence of these sublexical dimensions, this finding would provide support for the view that parallel activation of both languages is a feature of bilingualism itself.

To begin, we consider two roles that sublexical form plays in signed language processing. First, we ask whether the signed language syllable must be similar across two ASL translations in order to impact the processing of English orthographic forms in this experimental task. Wilbur (2011), among others, has proposed that the ASL syllable is based on the movement parameter. There is broad agreement that movement forms the nucleus of the signed language syllable. Some linguists further specify that movement and location together establish signed language syllables (Sandler, 1989), but there is only limited psycholinguistic evidence in support of this view (Dye \& Shih, 2006; Hildebrandt \& Corina, 2002). If cross-language activation of English and ASL relies on activation of the signed syllable, then we would expect to find coactivation when the translations of the English stimuli share the movement parameter (sharing handshape and movement or location and movement) but not for stimulus pairs whose translations share handshape and location.

Second, we consider a subset of the ASL lexicon in which there is a motivated relationship between ASL sublexical structure and English orthography. Specifically, some ASL signs have been modified to include a handshape that is associated with the first letter of the English orthographic word form. These handshapes are drawn from the fingerspelling system of ASL that allows signers to generate English orthographic forms. When these handshapes are used to associate ASL signs with their English orthographic translations, this form of language contact is referred to as initialization. The explicit ASL phonology to English orthography mapping captured in these handshapes could explain the findings of past studies of cross-language activation.

ASL-English bilinguals are an appropriate subset of deaf signing bilinguals in which to address this question. In a comparison of signed interpretations of a single discourse into four different signed languages, Nicodemus et al. (2017) found that the use of fingerspelling was more frequent in ASL than in any other signed language in their sample (Italian Sign Language [LIS], Irish Sign Language, and British, Australian, and New Zealand Sign Languages). Moreover, their participants explicitly stated that ASL signers are more likely to use fingerspelling than signers of other languages. While there are no studies documenting the distribution of initialization across different signed languages, initialization, like fingerspelling, appears to be particularly common in ASL. As an example, the sign for FAMILY in ASL is a modification of a sign referencing a set of entities. The sign starts with the two hands touching in front of the signers' torso. Each hand traces a symmetrical half-circle path in the transverse plane and meets the other hand to form a circular space, but 


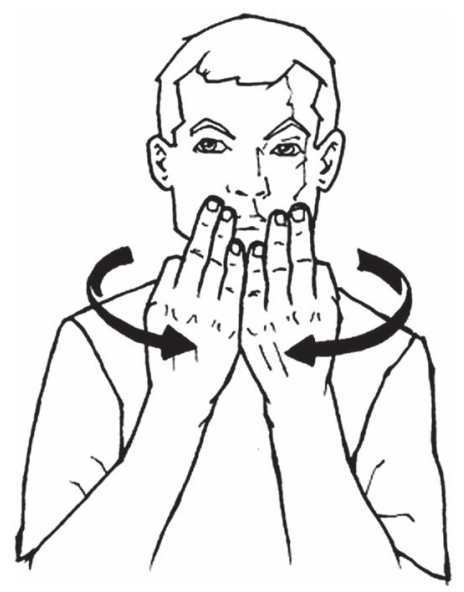

Figure 1 ASL sign for FAMILY. @ 2014, www.Lifeprint.com. Used by permission.

the hands are held in a handshape associated with the letter $F$ for the sign FAMILY. This lexical construction in ASL is fairly productive (Lepic, 2016). Several alphabetic handshapes can be used, while maintaining the core of the construction (grouping movement referencing a set of entities) to create other lexical signs in which the handshape is associated with the first letter of the orthographic representation of the English translation. For example, producing this construction with a $C$ handshape creates the ASL sign glossed in English as CLASS, while the use of the G handshape denotes the sign GROUP (see Figure 1).

If the use of initialization, a form of language contact between ASL and English, is driving cross-language activation, then we predict that we will only find cross-language activation for this subset of items. However, if the phonology-orthography relationship of initialized signs suppresses cross-language activation, then we may only find cross-language activation when there is no initialization. A third possibility is that initialized signs will participate in cross-language activation but not due to their status as initialized signs. This is because a pair of initialized signs differing only in handshape will share movement and location, the prototypical syllable described above. Even initialized pairs that are semantically unrelated share movement and location, such as the ASL signs WORLD and KIND (kind as in nominal type, not adjectival attribute), in which the $\mathrm{W}$ or $\mathrm{K}$ handshape on the dominant hand moves in a circular motion around the nondominant hand. Hence, our first prediction that an underlying shared syllable may be necessary for cross-language activation would be further supported if we find cross-language activation in the initialization condition and the syllable condition but not for signs that do not share a syllable.

Stimulus selection for a study of this type poses multiple challenges. Participants view English words, but the translations of those words in ASL are predicted to influence processing. Controlling lexical, sublexical, orthographic, and semantic dimensions of the stimuli in two languages has proven challenging in prior studies. In the current study as well, we find that control in one dimension constrains control along another dimension. We have prioritized selecting stimuli that share specific phonological parameters in ASL over fully controlling all other dimensions. To address this weakness of the study materials, we incorporated two forms of control. First, we asked bilingual participants to translate the English stimuli into ASL after completing the experiment so that we could selectively eliminate trials on which participants might not know or use the predicted ASL translations. Second, we analyzed the results

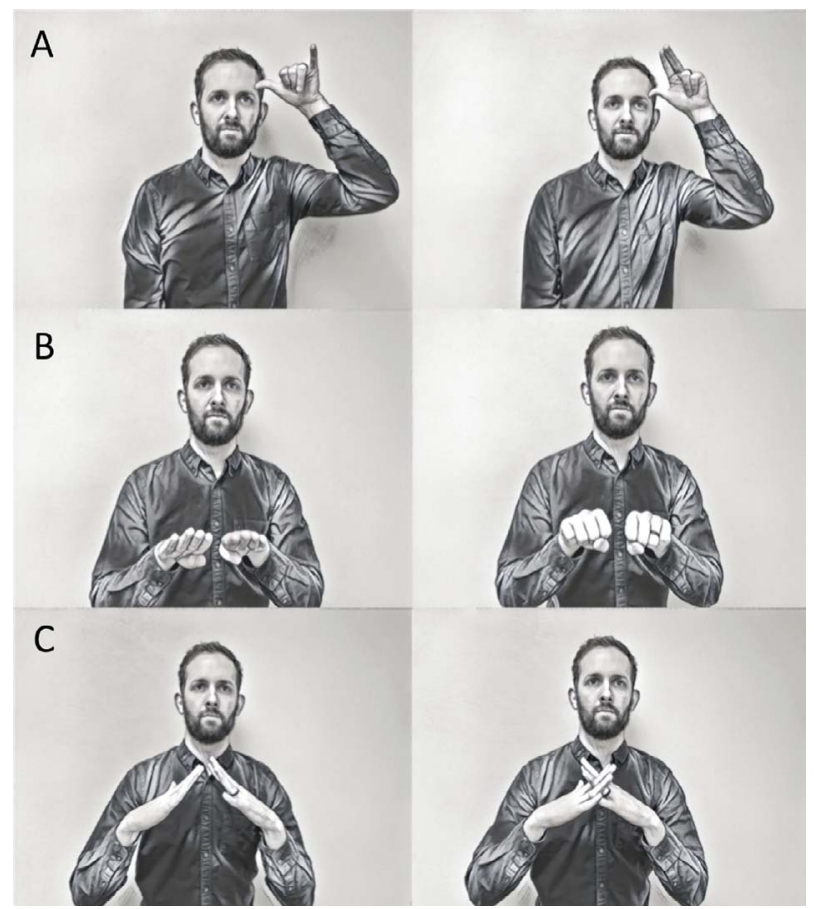

Figure 2 Phonologically related ASL signs. Panel A—sharing a syllable: cow, horse; Panel B-initialized ASL signs sharing a syllable: boots, shoes; Panel C-not sharing a syllable: football, wrestiling.

using mixed effects models to allow for random effects by item to be included in addition to random effects for participants, providing additional evidence that the cross-language activation effects reported are likely to be generalizable beyond the current study.

\section{Method}

The study employed a monolingual semantic similarity judgment task in English. Participants viewed two English words and responded yes to semantically related words and no to semantically unrelated words. Half of the stimulus pairs in both semantic conditions also had phonologically related ASL translations, although participants never saw the translations during the experiment. The ASL translations of the stimulus pairs could be phonologically related in one of three ways: (i) they shared a syllable, operationally defined as sharing the movement parameter in addition to either the location or handshape parameter (e.g., cow-horse, see Figure 2A); (ii) they were both initialized signs differing only in handshape (therefore, also sharing a syllable, e.g., boots-shoes, see Figure 2B); or (iii) they did not share a syllable but were nevertheless phonologically related through shared handshape and location (e.g., football-wrestling, see Figure 2C).

\section{Participants}

Two groups of participants completed the experiment: deaf bilinguals $(n=53)$, who used ASL and English on a daily basis, and hearing monolinguals $(n=43)$, who acquired English from birth and had no knowledge of ASL. The Deaf Bilingual group was further divided into two groups: deaf balanced bilinguals $(n=29)$, who were highly proficient in ASL and English, and deaf ASL-dominant bilinguals $(n=24)$, who were more proficient in ASL than in English. 
Table 1 Mean (SD) and range of background characteristics of deaf bilinguals

\begin{tabular}{lcccc}
\hline Participant group & $n$ (\# female) & Age [range] & ASL proficiency (ASL-SRT) & English proficiency (WJ, subtest 9) \\
\hline Deaf balanced bilinguals & $29(24$ female $)$ & $22[19,51]$ & $76 \%(12 \%)[45 \%, 95 \%]$ & $38(2.4)[35,43]$ \\
Deaf ASL-dominant bilinguals & $24(12$ female) & $24[18,46]$ & $66 \%(15 \%)[45 \%, 90 \%]$ & $31(2.7)[23,34]$ \\
\hline
\end{tabular}

Deaf participants were recruited from Gallaudet University and were paid $\$ 20 /$ hour for their participation in the experiment. Ninety participants were recruited through fliers targeting students who consider themselves bilingual in ASL and English. Data from 37 participants were eliminated: 5 due to equipment failure or experimenter error, 9 due to failure to complete the protocol or follow directions, 4 due to onset of deafness after age 2, 9 due to low accuracy (less than 80\% correct) on the experimental task, and 10 due to low accuracy (less than 45\% correct, cf. Morford et al., 2011, 2014) on the ASL assessment task. ASL proficiency was assessed with the American Sign Language-Sentence Repetition Task (ASL-SRT; Hauser, Paludnevičiené, Supalla, \& Bavelier, 2008). This study is one of the first to directly assess ASL proficiency in deaf participants rather than relying on parental hearing status to identify fluent signers of ASL. Direct assessment of ASL allowed us to recruit a broader cross-section of deaf bilinguals for potential participation in the study, but we also had to eliminate more participants on the basis of poor language skills as indicated either through low performance on the ASL-SRT or through low accuracy on the English experimental task. The remaining 53 participants completed the Woodcock-Johnson (WJ) III Tests of Achievement Passage Comprehension subtest. This specific assessment was selected because it evaluates the comprehension of English vocabulary and syntax without relying on sounds or oral stimuli. Twenty-nine participants scored 35 (grade equivalent, 8.9) or above on the WJ and were assigned to the deaf balanced bilinguals group. Twenty-four participants scored 34 or below and were assigned to the deaf ASL-dominant bilinguals group. Table 1 lists the number of females, the mean age, mean ASL-SRT, and mean WJ score for each group of deaf participants.

The hearing monolingual group was recruited from the undergraduate psychology pool at Penn State University and received course credit for completing the experiment. The average age of the 43 participants ( 37 female) was 19 (range, $[18,21])$. Participants in the control group that were born in the US were native speakers of English with no prior knowledge of ASL or any other signed language and had no history of hearing or speech disorders. Self-rated reading ability in English on a scale of 1 to 10 was at ceiling at $9.79(\mathrm{SD}=.51)$.

\section{Materials and Procedures}

Stimuli consisted of 336 English word pairs. Four hundred and forty English word pairs, with phonologically related $(n=220)$ and phonologically unrelated $(n=220)$ translation equivalents in ASL, were rated by hearing native speakers of English on a scale from 1 (semantically unrelated) to 7 (semantically related). Word pairs with mean ratings above 4.2 were classified as semantically related $(n=196)$, and pairs with mean ratings below 2.8 were classified as semantically unrelated $(n=170)$. In the semantically related condition, 98 English word pairs had phonologically related ASL translations (31 sharing a syllable, 45 initialized, and 22 that did not share a syllable but that shared handshape and location). In the semantically unrelated condition, 87 English word pairs had phonologically related ASL translations (42 sharing a syllable, 22 initialized, and 23 that did not share a syllable but that shared handshape and location). The remaining control stimuli had phonologically unrelated ASL translations and also did not differ from the experimental stimuli in degree of semantic similarity, word length in number of letters, or log frequency (see Appendix A, with log frequencies drawn from the English Lexicon Project database, http://elexicon.wustl.edu/).

All participants completed a background questionnaire. Deaf participants were assessed for proficiency in ASL (ASL-SRT; Hauser et al., 2008) and English (WJ Passage Comprehension subtest). The experimental task was programmed in E-Prime Professional 2.0 (Psychology Software Tools, Inc., Sharpsburg, PA). Participants first completed 10 practice trials with feedback, on which $80 \%$ accuracy had to be achieved before proceeding. Participants then completed two blocks of experimental trials. One block used a short stimulus onset asynchrony (SOA; $300 \mathrm{~ms}$ ) and one block used a long SOA $(750 \mathrm{~ms})$. The SOA variable was included to investigate the time course of cross-language activation; results are reported in another publication (Morford et al., 2017). Note that the SOA manipulation did not interact with the phonological relationship of the stimuli in English and ASL. Only data from the long SOA condition are analyzed in the current report to allow results in the current study to be compared with previous published studies, which all have used a longer SOA. The order of blocks and the assignment of stimulus lists to blocks were counterbalanced across participants. Each participant responded only once to a target word pair.

Experimental trials consisted of a $500 \mathrm{~ms}$ fixation cross, presentation of the first stimulus word for $250 \mathrm{~ms}$, a $500 \mathrm{~ms}$ interstimulus interval, followed by the second stimulus word, which remained on the screen until participants responded with a key press. Participants were instructed to decide whether the second English word was semantically related or unrelated to the first English word. ASL was not mentioned in the instructions and was not needed to complete the experimental task. Although participants interacted in ASL during the session for consenting and language assessment, the experimental task was completed entirely in English. Participants responded as quickly and accurately as possible by selecting a keyboard button labeled yes with their dominant hand or no with their nondominant hand. Only accurate responses were included in the analysis of reaction time (yes responses for the semantically related condition and no responses for the semantically unrelated condition).

To minimize the influence of lexical variation in ASL on the experimental results, deaf participants were asked to translate the English targets into ASL after completing the experimental task. If participants' translations did not conform to the condition criteria of phonological relatedness, then the trial was eliminated for that participant only. This resulted in the elimination of $6.4 \%$ of trials for the balanced bilingual group and $7.1 \%$ of trials for the ASL-dominant bilingual group. For example, for the English target candy, most signers produced a sign in which the index finger contacts the cheek and then is rotated. This sign is closely phonologically related to the ASL 
translation of the English word bored, produced with the same handshape and movement, but located at the side of the nose. This pair of targets was included in the semantically unrelated but phonologically related condition for shared syllable (candybored). However, several signers produced the polysemous ASL sign commonly glossed SUGAR in response to the English target candy. This sign differs in handshape, location, and movement from the ASL translation of the English word bored. For the specific participants who completed the translation task using the SUGAR variant in response to candy, the candy-bored trial was eliminated. Response times that were two standard deviations above and below the mean for each participant were also excluded. This resulted in the exclusion of $4.9 \%$ of the responses of the balanced bilingual group, $8.7 \%$ of the responses of the ASL-dominant bilingual group, and $4.6 \%$ of the hearing monolingual group.

\section{Analysis}

The data were analyzed with linear mixed effects models fitted with the lme4 (version 1.1-18-1) package in R (R Development Core Team, 2016; Bates, Mächler, Bolker, \& Walker, 2015) with design-driven maximal converging random effects specification. All models included random intercepts for participants and items. All random slopes and their interactions were modeled at the participant level. The dependent variable was reaction time, measured from the onset of the second stimulus to the time of participant's response.

Two models were fitted. The first model estimated the effects of cross-language activation of ASL translations of the English stimuli in the bilingual participants relative to the monolinguals in the semantically related and unrelated conditions. The second model focused solely on the bilinguals to determine whether the effects of cross-language activation identified in the first model were limited to trials on which stimuli had translations with shared syllabic structure or phonemegrapheme links from initialization. Moreover, the second model was fitted to determine whether these potential effects were identical for Balanced versus ASL-dominant bilinguals. The first model included fixed effects of (a) group (Monolingual $[n=43]$ versus Bilingual $[n=53]$ ), (b) semantics (semantically related versus unrelated), and (c) phonology (English stimuli had phonologically related or unrelated ASL translations) and the interactions of all three variables. The random effects structure included random slopes for semantics, phonology, and their interaction. The second model included fixed effects of (a) bilingual language experience (balanced bilingual $[n=29]$ versus ASL-dominant bilingual $[n=24]$ ), (b) phonology (English stimuli had phonologically related or unrelated ASL translations), and (c) phonological condition (syllable, initialization, and no syllable) and the interactions of all three variables. The random effects structure included random slopes for the effect of phonology, which were allowed to vary across each level of phonological condition. For the model effects, we report F-tests using Satterthwaite's method and, following significant interactions, simple contrasts with multiplicity-adjusted $p$-values using the multivariate $t$ distribution.

\section{Results}

The current study investigated whether deaf bilinguals activate ASL sign translations when reading English words, and if so, whether specific phonological dimensions drive cross- language activation from English to ASL. We asked participants to decide whether two English words were semantically related (cow-horse) or semantically unrelated (candy-bored). Half of the stimuli had phonologically similar translations in ASL. Table 2 shows the average response time to English word pairs for semantically related and unrelated words in the control and experimental conditions by deaf balanced bilinguals, deaf ASLdominant bilinguals and hearing monolinguals.

\section{Monolinguals vs. Bilinguals}

In a comparison of monolinguals and bilinguals, there were main effects of group and semantics on response time. Overall, bilinguals were faster to respond than monolinguals, $F(1,95.89)=6.74$, $p<.02$, and all participants responded more quickly on semantically related trials than on semantically unrelated trials, $F(1$, $208.23)=30.01, p<.001$. A significant semantics by phonology interaction indicated that phonological relatedness in ASL facilitated response time to English words in the semantically related condition (802 ms versus $768 \mathrm{~ms}$ ) but slowed response time in the semantically unrelated condition $(846 \mathrm{~ms}$ versus $861 \mathrm{~ms}), F(1,456.48)=3.99, p<.05$. Importantly, the two-way interaction was modulated by a three-way interaction of group, semantics and phonology, $F(1,95.20)=19.19, p<.001$. As seen in Figure 3 , the monolinguals were faster for semantically related than unrelated word pairs but were equally fast to respond in the phonologically related and unrelated conditions in each case. By contrast, bilingual participants' responses were facilitated by the phonological manipulation in the semantically related condition, but their responses were slowed by the phonological manipulation in the semantically unrelated condition. Simple contrasts indicated that the phonological facilitation effect for the bilinguals was significant (mean difference $=44.0 \mathrm{~ms}$, $p<.01$ ). Further, the bilinguals were significantly faster than the monolinguals for semantically related words that were also phonologically related in ASL (mean difference $=73.2 \mathrm{~ms}$, $p<.05)$. In the semantically unrelated condition, the inhibition effect did not reach significance (mean difference $=23.1 \mathrm{~ms}$, n.s.). However, the bilinguals were significantly faster than the monolinguals in the baseline condition for semantically unrelated pairs (mean difference $=108.7, p<.05$ ) but not in the experimental condition (mean difference $=81.3 \mathrm{~ms}$, n.s.) when the performance of the bilinguals was potentially slowed by the phonological manipulation.

\section{Balanced Bilinguals vs. ASL-Dominant Bilinguals}

In the second model focusing solely on the bilingual group, there was a significant main effect of phonology, $F(1,220.70)=7.83$, $p<.01$. Participants responded more rapidly to English word pairs with phonologically related ASL translations (729 ms) than to word pairs with phonologically unrelated translations (786 ms). Further, there was a main effect of phonological condition, $F(2,292.80)=15.62, p<.001$. Participants were faster when responding to the phonologically related and unrelated items in the syllable condition $(757 \mathrm{~ms})$ and the initialization condition $(738 \mathrm{~ms})$ relative to the no syllable condition $(810 \mathrm{~ms})$. These main effects were modulated by an interaction of phonology and phonological condition, $F(2,371.00)=3.64, p<.05$. Simple contrasts indicated that the effect of phonology (i.e. phonologically related versus unrelated conditions) reached significance for the no syllable condition (mean difference $=65.2 \mathrm{~ms}, p<.05$ ). Although there were mean differences in the expected direction for the initialization ( $63.1 \mathrm{~ms}, p=.07)$ and the syllable $(39.3 \mathrm{~ms}$, 
Table 2 Mean (se) response time and accuracy to control (phonologically unrelated) and experimental (phonologically related) conditions for deaf bilinguals and hearing monolinguals

\begin{tabular}{lllll}
\hline & \multicolumn{2}{c}{ Semantically related } & \multicolumn{2}{c}{$\begin{array}{c}\text { Semantically unrelated } \\
\text { Phonologically related }\end{array}$} \\
& Phonologically unrelated & Phonologically related & Phonologically unrelated & Pho \\
\hline Deaf balanced bilinguals & $776(49) 82 \%$ & $716(46) 80 \%$ & $762(50) 93 \%$ & $788(52) 88 \%$ \\
Deaf ASL-dominant bilinguals & $798(55) 82 \%$ & $746(57) 80 \%$ & $825(59) 89 \%$ & $858(62) 85 \%$ \\
Hearing English monolinguals & $817(39) 84 \%$ & $807(42) 81 \%$ & $902(45) 88 \%$ & $903(43) 88 \%$ \\
\hline
\end{tabular}

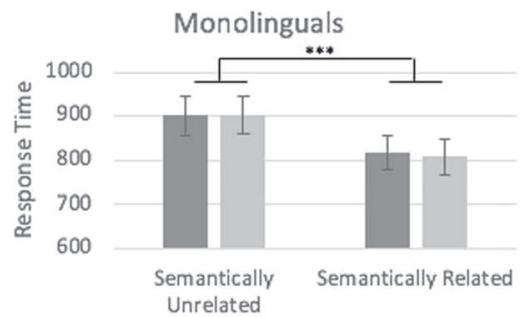

ص Phonologically Unrelated = Phonologically Related

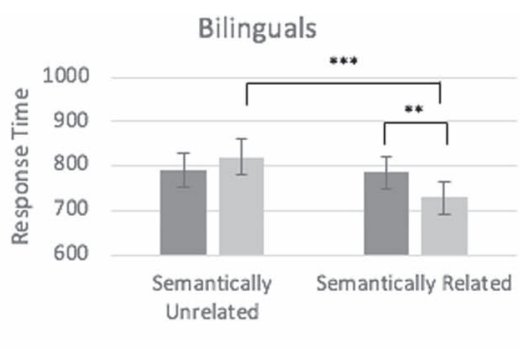

E. Phonologically Unrelated $=$ Phonologically Related

Figure 3 Three-way interaction of group, semantics, and phonology on response time (in milliseconds).

n.s.) conditions, they did not reach significance. No significant differences were found between balanced bilinguals and ASLdominant bilinguals.

\section{Discussion}

The current study adds to the growing consensus that crosslanguage activation influences language processing in all bilinguals regardless of language modality. Evidence that deaf bilinguals activate signed language forms during written word processing spans many different signed languages, including ASL (Morford et al., 2011; Meade et al., 2017; Quandt \& Kubicek, 2018), Chinese Sign Language (Pan et al., 2015), German Sign Language (Kubuş et al., 2015), LIS (Bonsignori \& Demestre, 2018), Mexican Sign Language (Mendoza et al., 2018), NGT (Ormel et al., 2012), and Taiwanese Sign Language (Chiu et al., 2016). Like unimodal spoken language bilinguals, lexical access for deaf bilinguals is language nonselective. Moreover, this is the second study to demonstrate that deaf bilinguals activate signs while reading written words, regardless of whether their proficiency in the signed language is much greater than in the spoken language or whether they have attained a high level of proficiency in both languages (cf. Morford et al., 2014). Indeed, no significant differences were found in the performance of balanced bilinguals and ASL-dominant bilinguals in the current study. Hence, activation of signs during written word processing appears to be the norm for signing bilinguals rather than a transitory characteristic of L2 learning.

The current study did not replicate the inhibition effect that has been found in prior studies of cross-language activation using the same paradigm. In contrast to other studies investigating these types of effects, our approach in the current study was to use mixed effects linear modeling. Type I error rates are very nearly eliminated in statistical approaches that include random effects of participants and items, but type II errors increase with variation in participant performance to a greater extent than in statistical models that do not include random effects (Johnson, 2009). Future studies of cross-language activation are needed to evaluate whether effects of inhibitory conflict between ASL phonological similarity and English semantic differences can be reliably detected. Further, future studies may need to employ different tasks to investigate the relative contributions of inhibition and facilitation as these effects may reflect different cognitive mechanisms related to cognitive control and language regulation (Fricke, Zirnstein, Navarro-Torres, \& Kroll, 2019; Zirnstein, Van Hell, \& Kroll, 2018).

This study aimed to specify whether specific sublexical structures underlie cross-language activation in deaf signing bilinguals. Specifically, we asked whether activated ASL signs had to share a syllable to influence a semantic judgment task involving written English words. By controlling for the phonological parameters shared by the ASL translations of the English stimuli, we isolated conditions where the translations shared a syllable, versus conditions where the translations overlapped in a combination of parameters not associated with syllable structure (i.e., handshape and location) in traditional models of signed language phonology. If the signed language syllable, according to these models, was central to crosslanguage activation of signs during written word processing, then we expected to find effects only when the ASL translations shared a syllable. However, this was not the case. Evidence of cross-language activation was strongest when the translations overlapped in handshape and location, a combination of parameters that is not central to any theory of signed language syllabic structure.

We also investigated whether a form of language contact unique to signed and spoken languages might be driving crosslanguage activation in deaf bilinguals. Specifically, ASL has a set of signs that have undergone phonological changes to reflect the orthography of the English translation. ASL signs such as FAMILY and CLASS are variants of a lexical construction referring to a set of entities. Because these initialized signs have a direct link to English orthography, they could play a special role in cross-language activation. However, the results showed that this condition alone was also not responsible for generating an effect of cross-language activation.

If cross-language activation is not generated by the spread of activation across shared syllabic structure within ASL or by associations of English orthography with ASL phonology, then what explains the fact that deaf bilinguals activate ASL signs while processing English print? Given the results of the current 
study, we propose that cross-language activation in bilinguals is best explained by neural network models that make no a priori assumptions about the best mappings of language form and meaning across two languages, such as Shook and Marian's (2013) Bilingual Language Interaction Network for Comprehension of Speech (BLINCS). Although BLINCS is a model of bilingual speech comprehension, it is ideal for explaining how deaf bilinguals manage to build relationships across two languages that have little shared articulatory, perceptual, or orthographic forms. It does so by incorporating self-organizing maps, which model unsupervised learning, to explain how sensory input is dynamically mapped to phonological and semantic representations within and across levels of representation. This type of model can account for the fact that no single type of sublexical relationship (e.g., syllabic, initialization, etc.) underlies cross-language activation of the L1 (ASL) during L2 (English) processing. Learners discover relationships within and across both languages and levels of language representation, which are driven by dimensions of the sensory input that form patterns. The advantage of self-organizing maps as a means of modeling these patterns is that the modeler does not select the dimensions; the dimensions are determined by the distributional properties of the input. Although orthographic systems are designed to capture phonological patterns of the spoken language they represent, self-organizing maps allow for the possibility that, depending on the degree of auditory input, deaf learners may detect orthography-phonology mappings at the level of the segment, the bigram, the syllable, or the whole word. These maps may incorporate articulatory patterns from mouthing in addition to or instead of auditory patterns, as well as manual articulatory patterns. This type of model predicts that deaf learners will discover the most reliable relationships in the input between English orthography, ASL phonology, and semantics, even if this means bypassing the design features of the orthographic system to capture spoken phonological patterns (cf. Costa, Pannunzi, Deco, \& Pickering, 2017, Hermans, Ormel, \& Knoors, 2010, and Hoffmeister \& Caldwell-Harris, 2014, for additional accounts of cross-language phonological mapping).

Consider an example of competing associations that can be discovered between English and ASL. While the English orthographic system was not designed to capture ASL phonological patterns, the ASL fingerspelling system and by extension ASL handshapes occurring in initialized signs were designed to represent written forms in English. Thus, it is no accident that many of the ASL fingerspelled alphabetic handshapes share some formal representation with English orthography (see Figure 4). Nevertheless, ASL fingerspelling handshapes pattern not only with respect to English orthography but also with respect to the distribution of all handshapes across ASL signs. That is to say, while the L handshape participates in lexical constructions in which the handshape is likely construed as representing English orthographic "L", the same handshape also participates in lexical constructions in which the handshape is construed as showing the corner of a rectangular object. These competing construals lead to ambiguous cases of initialization, such as LICENSE, in which the two L handshapes form three sides of a rectangle, outlining the shape of a driver's license. When signers associate the ASL sign LICENSE with the English orthographic form "license", they may build associations between the handshape and the shape of the referent and/or with the first letter of the English translation. These associations are subject to further influence from morphologically related signs such as LICENSE-EXPIRE, where one of the L handshapes is rotated to show that the

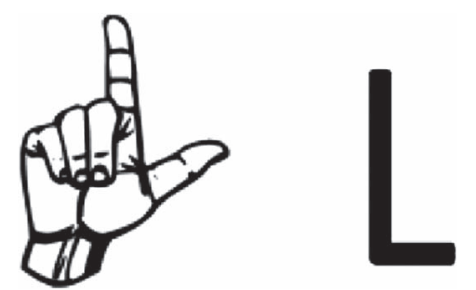

Figure 4 ASL fingerspelled handshape for "L" and English orthographic form for "L". Handshape image ๑ 2014, www.Lifeprint.com. Used by permission.

LICENSE is no longer intact. Movement of the L handshape out of the standard orientation for fingerspelling may lead signers to create stronger associations between the shape construal of the handshape in LICENSE and LICENSE-EXPIRE than the English orthography construal. Finally, the L handshape participates in constructions in which the handshape most certainly does not make reference to English orthography at all, as in WELD, which is an enactment of welding with the $\mathrm{L}$ handshape construed as the torch.

Language internal forces (analogy based on existing morphological constructions), loss of cultural connection (analyzability of original motivation is lost), or simple language change (semantic bleaching, shift, or extension) may "pull" a handshape away from its original, historically accurate, motivated source. Thus, the ability to detect patterns in ASL phonology and English orthography depends on language exposure but also to some extent on meta-awareness of the original intent to formally represent orthography through handshapes. Young ASL learners acquire fingerspelled forms and initialized signs without any awareness of the relationship of ASL fingerspelling to English orthography, long before they begin learning to read (Erting, Thumann-Prezioso, \& Benedict, 2000). Padden (2006) has referred to this acquisition pattern as "learning to fingerspell, twice." It is only following greater experience with English orthography that ASL-English bilinguals discover the original motivations of the handshapes used in fingerspelling and initialization. In much the same way, English L2 learners of French initially associate the English word rouge only with the meaning "blush", but exposure to French ultimately leads them to discover the historical motivation of the English word when the French color word rouge meaning "red" is acquired. In sum, even when ASL phonology and English orthography align by design, the learner may not initially discover these patterns when acquiring either language, or in other cases the alignment may become apparent for some signers but not for others. The phonological patterns underlying cross-language activation in deaf bilinguals clearly extend well beyond the subset of initialized signs in the ASL lexicon.

The results of this study also raise the possibility that current models of signed language phonology do not capture the relevant dimensions to distinguish effects of different sublexical parameters on cross-language activation. Traditional attempts to describe the phonology of signed languages are rooted in linguistic models that assume that phonology is an abstract formal system independent of semantics. Usage-based models of phonology (Bybee, 2001) do not consider phonological content to be independent from the rest of the grammar. Recent work on one such usage-based model, cognitive phonology, investigates how sublexical units of varying sizes of formal complexity emerge from iterations of language use, and how these forms retain and even gain meaningful associations over time (Wilcox, 2004; Occhino, 2016, 2017). As form and meaning are encountered together, new tokens of use are 
stored with existing exemplars along dimensions of similarity. In a system where phonology is extracted from semantically and pragmatically rich iterations of language use, treatment of individual phonological parameters as minimal contrastive units, devoid of meaning, obscures the extent to which meaning can be maintained and even developed in phonemic and subphonemic units as they repeatedly occur in regular and predictable environments within the grammar. Far from being devoid of meaning, signs that overlap in, for example, handshape and location, may also share a common interpretation of those parameters (e.g. mouth as the location of eating, kissing, or speaking). Therefore, it is possible that these parameter overlaps are actually functioning similarly to what would traditionally be considered morphological overlap. There were insufficient tokens of any specific phonological mapping in the current dataset to be able to further delve into issues of phonological motivation. Additional studies, which take a cognitive approach to phonology, may shed light on such matters. What is clear, however, is that the complex interplay between signed and spoken language representations affords multiple ways in which form and meaning can be mapped within and across modalities.

The goal of this study was not to evaluate whether deaf bilinguals are slower than monolinguals when processing words in their L2, but the results are a remarkable demonstration that this was absolutely not the case. As Coderre, Van Heuven, and Conklin (2013) pointed out, studies from a wide range of languages, methods, and bilinguals repeatedly find slower production and comprehension of L2 words relative to monolingual performance on the same tasks. By contrast, the current study found that deaf bilinguals were significantly faster than monolinguals, despite the fact that the monolinguals were a uniform population of college students responding to words in their native language. Further, accuracy levels were comparable despite the faster response times (see Table 2). For hearing bilinguals, the overwhelming evidence of slower L2 processing is assumed to reflect a less efficient but comparable use of the same processes used for the L1. For deaf bilinguals, the same assumption is not warranted. It is possible that the faster performance of the deaf participants is completely unrelated to language processing; deaf participants may benefit from the reorganization of visual selective attention (Dye, Hauser, \& Bavalier, 2009) or have had higher intrinsic motivation to perform well on this task. Deaf bilinguals also differ from hearing bilinguals because they master completely unique sensory patterns for their first and second languages. The visual signals of moving hands for the signed language and static sequences of orthographic patterns and dynamically patterned mouth movements for the spoken language share only the fact that they are patterns linked to semantics. Deaf bilinguals acquiring a spoken language as their L2 may face a steeper learning curve due to a lack of transfer from their signed language, but ultimately benefit from any and all associations generated between the two language systems by virtue of the absence of sensory or form-based competition between L1 and L2 phonological and orthographic patterns (cf. Morford et al., 2017).

One promising avenue for unraveling some of the outstanding questions raised here would be to begin investigating the interaction of ASL and English in deaf bilingual children who are still developing proficiency in both languages. Studies of bilingual children who know two spoken languages have found evidence for cognate facilitation (Poarch \& Van Hell, 2012) as well as cross-language inhibition (Von Holzen \& Mani, 2012). However, these effects are found in bilinguals whose languages share phonological forms. For bilinguals who know a signed and a spoken language, parallel activation of signs and words may be the outcome of lifelong experience activating and using word forms of both languages in bilingual contexts, rather than from direct competition of word forms sharing phonological features, segments, or syllables. If this is the case, then deaf children may initially associate English orthography only with English phonology and show little or no evidence of crosslanguage activation. By contrast, if young deaf children acquire L2 English orthographic forms by associating them with their ASL translation equivalents, then deaf children, like adults, may show simultaneous activation of words and signs from the start (cf. Ormel et al., 2012).

Studies investigating cross-language activation in deaf signing bilinguals will also continue to add to the multi-faceted domain of bilingual language processing. This study provides evidence of the robust nature of cross-language activation in the absence of shared language forms-spoken, signed, or writtenand in the absence of task requirements for language switching. Nonselective access of lexical forms is a fundamental characteristic of bilingual processing arising from the use of multiple languages in meaningful contexts rather than from the need to assign ambiguous forms to their respective languages. Shared phonological and orthographic forms have provided a productive avenue for investigating how bilinguals manage their linguistic resources, but a complete theory of bilingual language processing must account for cross-language interactions when ambiguity does not exist.

\section{Funding}

National Science Foundation Science of Learning Center Program (SBE-0541953, SBE-1041725 to the Visual Language and Visual Learning (VL2) Science of Learning Center).

\section{Conflict of Interest}

No conflicts of interest were reported.

\section{Acknowledgement}

Many thanks to our participants as well as student and faculty collaborators: Selina Agyen, Benjamin Anible, Rich Bailey, Brian Burns, Yunjae Hwang, Teri Jaquez, Asha Rajashekhar, and Paul Twitchell. Correspondence concerning this article should be addressed to Jill P. Morford, Department of Linguistics, University of New Mexico, Albuquerque, NM 87131. Contact: morford@unm.edu.

\section{References}

Bates, D., Mächler, M., Bolker, B., \& Walker, S. (2015). Fitting linear mixed-effects models using lme4. Journal of Statistical Software, 67(1), 1-48. doi:10.18637/jss.v067.i01

Bonsignori, C., \& Demestre, J. (2018). Cross-language activation in deaf Italian Sign Language (LIS)-Italian bilinguals. Paper presented at The Fourth St. Petersburg Winter Workshop on Experimental Studies of Speech and Language.

Bybee, J. L. (2001). Phonology and language use. Cambridge, MA Cambridge University Press.

Chiu, Y.-S., Kuo, W.-J., Lee, C.-Y., \& Tzeng, O. J. L. (2016). The explicit and implicit phonological processing of Chinese characters and words in Taiwanese deaf signers. Language and Linguistics, 17(1), 63-87. doi:10.1177/1606822X15614518

Coderre, E. L., van Heuven, W. B., \& Conklin, K. (2013). The timing and magnitude of Stroop interference and facilitation 
in monolinguals and bilinguals. Bilingualism: Language and Cognition, 16(2), 420-441. doi:10.1017/S1366728912000405

Costa, A., Pannunzi, M., Deco, G., \& Pickering, M. J. (2017). Do bilinguals automatically activate their native language when they are not using it? Cognitive Science, 41(6), 1629-1644. doi:10.1111/cogs.12434

Dias, P., Villameriel, S., Giezen, M. R., Costello, B., \& Carreiras, M. (2017). Language switching across modalities: Evidence from bimodal bilinguals. Journal of Experimental Psychology: Learning, Memory, and Cognition, 43(11), 1828-1834. doi:10.1037/xlm0000402

Dye, M. W. G., Hauser, P. C., \& Bavelier, D. (2009). Is visual attention in deaf individuals enhanced or deficient? The case of the useful field of view. PLoS One, 4(5), e5640. doi:10.1371/journal.pone. 0005640

Dye, M. W. G., \& Shih, S. (2006). Phonological priming in British Sign Language. In L. M. Goldstein, D. H. Whalen \& C. T. Best (Eds.), Laboratory Phonology 8 (pp. 241-263). Berlin, Germany: Mouton de Grutyer.

Erting, C. J., Thumann-Prezioso, C., \& Benedict, B. (2000). Bilingualism in a deaf family: Fingerspelling in early childhood. In P. E. Spencer, C. J. Erting \& M. Marschark (Eds.), The deaf child in the family and at school: Essays in honor of Kathryn P. Meadow-Orlans (pp. 41-54). Mahwah, NJ: Lawrence Erlbaum

Fricke, M., Zirnstein, M., Navarro-Torres, C., \& Kroll, J. F. (2019). Bilingualism reveals fundamental variation in language processing. Bilingualism: Language and Cognition, 22(1), 200-207. doi:10.1017/S1366728918000482

Giezen, M. R., Blumenfeld, H. K., Shook, A., Marian, V., \& Emmorey, K. (2015). Parallel language activation and inhibitory control in bimodal bilinguals. Cognition, 141, 9-25. doi:10.1016/j.cognition.2015.04.009

Hauser, P. C., Paludnevičienè, R., Supalla, T., \& Bavelier, D. (2008). American Sign Language-Sentence Reproduction Test. In R. M. de Quadros (Ed.), Sign languages: Spinning and unraveling the past, present and future. TISLR 9, forty-five papers and three posters from the 9th Theoretical Issues in Sign Language Research Conference, Florianopolis, Brazil, December 2006 (pp. 160-172). Editora Arara Azul: Petrópolis/RJ, Brazil.

Hermans, D., Ormel, E., \& Knoors, H. (2010). On the relation between the signing and reading skills of deaf bilinguals. International Journal of Bilingual Education and Bilingualism, 13(2), 187-199. doi:10.1080/13670050903474093

Hildebrandt, U. C., \& Corina, D. P. (2002). Phonological similarity in American Sign Language. Language and Cognitive Processes, 17(6), 593-612. doi:10.1080/01690960143000371

Hoffmeister, R. J., \& Caldwell-Harris, C. L. (2014). Acquiring English as a second language via print: The task for deaf children. Cognition, 132, 229-242. doi:10.1016/j.cognition.2014.03.014

Hosemann, J., Altvater-Mackensen, N., Herrman, A., \& Mani, N. (2013). Cross-modal language activation. Does processing a sign (L1) also activate its corresponding written translations (L2)? Presented at the 11th Theoretical Issues in Sign Language Research Conference, London.

Johnson, D. E. (2009). Getting off the GoldVarb standard: Introducing Rbrul for mixed-effects variable rule analysis. Language and Linguistics Compass, 3(1), 359-383. doi:10.1111/j.1749-818x.2008.00108.x

Kubuş, O., Villwock, A., Morford, J. P., \& Rathmann, C. (2015). Word recognition in deaf readers: Cross-language activation of German Sign Language and German. Applied Psycholinguistics, 36(4), 831-854. doi:10.1017/S0142716413000520
Lepic, R. (2016). Motivation in morphology: Lexical patterns in ASL and English (Dissertation). University of California, San Diego.

Meade, G., Midgley, K. J., Sevcikova Sehyr, Z., Holcomb, P. J., \& Emmorey, K. (2017). Implicit co-activation of American Sign Language in deaf readers: An ERP study. Brain and Language, 170, 50-61. doi:10.1016/j.bandl.2017.03.004

Mendoza, E., Jackson Maldonado, D., \& Morán, K. (2018). Spanish word recognition in Mexican deaf signers. Poster presented at the 3rd International Conference on Sign Language Acquisition, Istanbul, Turkey.

Morford, J. P., Kroll, J. F., Piñar, P. \& Wilkinson, E. (2014) Bilingual word recognition in deaf and hearing signers: Effects of proficiency and language dominance on cross-language activation. Second Language Research, 30(2), 251-271. doi:10.1177/0267658313503467

Morford, J. P., Occhino, C., Piñar, P., Wilkinson, E., \& Kroll, J. F. (2017). The time course of cross-language activation in deaf ASLEnglish bilinguals. Bilingualism: Language and Cognition, 20(2), 337-350. doi:10.1017/S136672891500067X

Morford, J. P., Wilkinson, E., Villwock, A., Piñar, P., \& Kroll, J. F. (2011). When deaf signers read English: Do written words activate their sign translations? Cognition, 118(2), 286-292. doi:10.1016/j.cognition.2010.11.006

Nas, G. (1983). Visual word recognition in bilinguals: Evidence for a cooperation between visual and sound based codes during access to a common lexical store. Journal of Verbal Learning and Verbal Behavior, 22, 526-534. doi:10.1016/S0022-5371(83)90319-5

Nicodemus, B., Swabey, L., Leeson, L., Napier, J., Petitta, G., \& Taylor, M. M. (2017). A cross-linguistic analysis of fingerspelling production by sign language interpreter. Sign Language Studies, 17(2), 143-171. doi:10.1353/sls.2017.0000

Occhino, C. (2016). A cognitive approach to phonology: Evidence from signed languages (Dissertation). University of New Mexico, Albuquerque, NM.

Occhino, C. (2017). An introduction to embodied cognitive phonology: Claw-5 handshape distribution in ASL and Libras. Complutense Journal of English Studies, 25, 69-103. doi:10.5209/CJES.57198

Ormel, E., Hermans, D., Knoors, H., \& Verhoeven, L. (2012). Crosslanguage effects in written word recognition: The case of bilingual deaf children. Bilingualism: Language and Cognition, 15(2), 288-303. doi:10.1017/S1366728911000319

Padden, C. A. (2006). Learning to fingerspell twice: Young signing children's acquisition of fingerspelling. In B. Schick, M. Marschark \& P. E. Spencer (Eds.), Advances in the sign language development of deaf children (pp. 189-201). Oxford: Oxford University Press.

Pan, J., Shu, H., Wang, Y., \& Yan, M. (2015). Parafoveal activation of sign translation previews among deaf readers during the reading of Chinese sentences. Memory \& Cognition, 43, 964-972. doi:10.3758/s13421-015-0511-9

Poarch, G. J., \& Van Hell, J. G. (2012). Cross-language activation in children's speech production: Evidence from second language learners, bilinguals, and trilinguals. Journal of Experimental Child Psychology, 111(3), 419-438. doi:10.1016/j.jecp.2011.09.008

Quandt, L. C., \& Kubicek, E. (2018). Sensorimotor characteristics of sign translations modulate EEG when deaf signers read English. Brain and Language, 187, 9-17. doi:10.1016/j.bandl.2018.10.001

R Development Core Team (2016). R: A Language and Environment for Statistical Computing (). Vienna, Austria: R Foundation for Statistical Computing. 
Sandler, W. (1989). Phonological representation of the sign: Linearity and nonlinearity in American Sign Language. Dordrecht: Foris.

Schwartz, A. I., \& Van Hell, J. G. (2012). Bilingual visual word recognition in sentence context. In J. S. Adelman \& J. S. Adelman (Eds.), Visual word recognition: Meaning and context, individuals and development (Vol. 2pp. 131-150). New York, NY: Psychology Press.

Shook, A., \& Marian, V. (2012). Bimodal bilinguals co-activate both languages during spoken comprehension. Cognition, 124(3), 314-324. doi:10.1016/j.cognition.2012.05.014

Shook, A., \& Marian, V. (2013). The Bilingual Language Interaction Network for Comprehension of Speech. Bilingualism: Language and Cognition, 16, 304-324. doi:10.1017/S1366728912000466

Thierry, G., \& Wu, Y. J. (2007). Brain potentials reveal unconscious translation during foreign language comprehension. Proceeding of National Academy of Sciences of the United States of the America, 104(30), 12530-12535. doi:10.1073/pnas.0609927104

Thompson, R., \& Langdon, C. (2018). Cross-modal bilingual activation in English \& American Sign Language bilinguals: The role of language experience. Paper presented at the 31st Annual CUNY Sentence Processing Conference, Davis, CA.

Villameriel, S., Dias, P., Costello, B., \& Carreiras, M. (2016). Crosslanguage and cross-modal activation in hearing bimodal bilinguals. Journal of Memory and Language, 87, 59-70. doi:10.1016/j.jml.2015.11.005

Von Holzen, K., \& Mani, N. (2012). Language nonselective lexical access in bilingual toddlers. Journal of Experimental Child Psychology, 113(4), 569-586. doi:10.1016/j.jecp.2012.08.001

Wilbur, R. (2011). Sign syllables. In M. van Oostendorp, C. J. Ewen, E. Hume \& K. Rice (Eds.), The Blackwell companion to phonology (pp. 1309-1334). Oxford: Wiley Blackwell.

Wilcox, S. (2004). Cognitive iconicity: Conceptual spaces, meaning, and gesture in signed languages. Cognitive Linguistics, 15 (2), 119-147. doi:10.1515/cogl.2004.005

Wu, Y. J., \& Thierry, G. (2010). Chinese-English bilinguals reading English hear Chinese. The Journal of Neuroscience, 30(22), 7646-7651. doi:10.1523/JNEUROSCI.1602-10.2010

Zirnstein, M., Van Hell, J. G., \& Kroll, J. F. (2018) Cognitive control ability mediates prediction costs in monolinguals and bilinguals. Cognition, 176, 87-106. doi:10.1016/j.cognition.2018.03.001

\section{Lexical characteristics of the English stimuli (Total and by phonological condition)}

Semantically related

\begin{tabular}{|c|c|c|c|c|c|}
\hline & Phonologica & elated & Phonologice & ted & t-test \\
\hline \multirow[t]{5}{*}{ Semantic similarity rating $(1-7)$} & \multicolumn{2}{|l|}{$5.4(.6)$} & \multicolumn{2}{|l|}{$5.4(.6)$} & \multirow[t]{5}{*}{ n.s. } \\
\hline & \multicolumn{2}{|c|}{ By phonological condition } & \multicolumn{2}{|c|}{ By phonological condition } & \\
\hline & Syllable & 5.2 & Syllable & 5.2 & \\
\hline & Initialized & 5.4 & Initialized & 5.5 & \\
\hline & No syllable & 5.5 & No syllable & 5.4 & \\
\hline \multirow[t]{4}{*}{ Word length (\# letters) } & $5.8(2.2)$ & & $6.1(2.3)$ & & \multirow[t]{4}{*}{ n.s. } \\
\hline & Syllable & 5.7 & Syllable & 5.8 & \\
\hline & Initialized & 6.2 & Initialized & 6.6 & \\
\hline & No syllable & 5.6 & No syllable & 6.1 & \\
\hline \multirow[t]{4}{*}{ HAL Log Frequency } & $10.1(1.6)$ & & $9.9(1.7)$ & & \multirow[t]{4}{*}{ n.s. } \\
\hline & Syllable & 10.2 & Syllable & 10.0 & \\
\hline & Initialized & 9.7 & Initialized & 10.0 & \\
\hline & No syllable & 10.1 & No syllable & 9.8 & \\
\hline
\end{tabular}

Semantically unrelated

\begin{tabular}{|c|c|c|c|c|c|}
\hline & \multicolumn{2}{|c|}{ Phonologically unrelated } & \multicolumn{2}{|c|}{ Phonologically related } & t-test \\
\hline \multirow[t]{5}{*}{ Semantic similarity rating (1-7) } & \multirow{2}{*}{\multicolumn{2}{|c|}{$\begin{array}{l}1.25(.66) \\
\text { By phonological condition }\end{array}$}} & \multirow{2}{*}{\multicolumn{2}{|c|}{$\begin{array}{l}1.36(.71) \\
\text { By phonological condition }\end{array}$}} & \multirow[t]{5}{*}{ n.s. } \\
\hline & & & & & \\
\hline & Syllable & 1.2 & Syllable & 1.3 & \\
\hline & Initialized & 1.3 & Initialized & 1.5 & \\
\hline & No syllable & 1.2 & No syllable & 1.4 & \\
\hline \multirow[t]{4}{*}{ Word length (\# letters) } & $5.7(1.8)$ & & $5.9(2.2)$ & & \multirow[t]{4}{*}{ n.s. } \\
\hline & Syllable & 5.4 & Syllable & 5.7 & \\
\hline & Initialized & 6.8 & Initialized & 7.2 & \\
\hline & No syllable & 5.6 & No syllable & 5.6 & \\
\hline \multirow[t]{4}{*}{ HAL log frequency } & $9.8(1.7)$ & & $9.9(1.6)$ & & \multirow[t]{4}{*}{ n.s. } \\
\hline & Syllable & 9.9 & Syllable & 10.0 & \\
\hline & Initialized & 9.7 & Initialized & 9.9 & \\
\hline & No syllable & 9.6 & No syllable & 10.0 & \\
\hline
\end{tabular}

